\title{
IS BANGLADESH READY TO COPE WITH HER FUTURE DISEASE BURDEN?
}

Bangladesh is the most densely populated (913 per sq. $\mathrm{km}$ ) country in the world. She is exposed to natural calamities like flood, cyclone and tidal bore almost every year. Her population suffers from poverty, illiteracy and malnutrition. These three major factors produce a vicious cycle. High prevalence of low birth weight and protein energy malnutrition and parasitosis among infants and children leads to impaired immunity and susceptibility to infections; consequently, there is slower recovery, higher morbidity, higher disability and a higher mortality. Malnutrition and frequent infections in early life affects both growth (increase in physical size of the body) and development (increase in skills and functions). Thus, Bangladesh is being populated with an increasing proportion of inefficient and disabled man power. This results in severe limitations in national growth and development caught in this vicious cycle spanning from one generation to the next.

According to mortality estimates of eight regions of the world in 1990, $98 \%$ of all deaths in children younger than 15 years are in the developing world ${ }^{1}$. The communicable diseases (CDs), maternal, perinatal, and nutritional disorders accounted for 17.2 million deaths, non-communicable diseases for 28.1 million deaths and injuries for 5.1 million deaths. Overall, five of the ten leading killers are CDs, perinatal, and nutritional disorders largely affecting children of the developing or disadvantaged communities. The noncommunicable diseases (NCDs) were also found to be major public health challenges in the developing counties. Injuries, which account for $10 \%$ of global mortality, are often ignored as a major cause of death. It is likely that as a least developing country, Bangladesh has the same disease burden of both CDs and NCDs. For Bangladesh, we have very little information in this regard. There are some recent reports on the prevalence of diabetes ${ }^{2}$, hypertension ${ }^{3}$ and metabolic syndrome ${ }^{4}$ indicating that the prevalence of NCDs is on the increase ${ }^{5}$. Additionally, there are other population based studies that addressed nutritional status among the rural women and children. Some of these studies were recently conducted by the Department of Community Medicine, utilizing the students of Ibrahim Medical College in the community surveys as part of their academic exercise ${ }^{6}$. Three more studies are published elsewhere in this issue ${ }^{7-9}$. Although the sample sizes were small, these studies explored some important health problems, which are consistent with the above mentioned report ${ }^{1}$.

So we have to consider the present disease load of malnutrition and CDs in the vast majority who are chronically exposed to extreme poverty and unhygienic environment creating a 'susceptible population' to be invaded by more and more diseases. Added to this, there has been an alarming increase of NCDs leading to chronic disabilities like stroke, nephropathy, retinopathy (even blindness), leg amputation etc. In short, we are finding the entire population on the verge of a disease disaster.

What do we have to cope with this future disease burden? As we plan for future needs, we must also look for reasons for failures to contain the disease burden. The most common reasons are failure of compliance of Primary Health Care (PHC) like - a) a poor budgetary allocation for the health care b) equitable (not equal) distribution of health care is yet to be implemented and c) unavailability of and inaccessibility to health care. Even more important, as we see, is the lack of appropriate training and development of health personnel. A physician is a leader of a health team. The physician must be capable of guiding the health team. Therefore we must now look for quality in medical education and revival of moral and ethical values in professional conduct. It is imperative to address these issues with priority. We recommend that the possible implications of these needs and changing trends for human and economic development in a poorlyresourced healthcare setting in Bangladesh be addressed immediately to cope with the future disease burden.

\author{
Md. Abu Sayeed \\ Professor \\ Department of Community Medicine \\ Ibrahim Medical College
}

\section{References}

1. Murray CJ, Lopez AD. Mortality by cause for eight regions of the world: Global Burden of Disease Study. Lancet 1997; 349(9061): 1269-76. 
2. Sayeed MA, Banu A, Khan AR and Hussain MZ. Prevalence of diabetes and hypertension in a rural population of Bangladesh. Diabetes Care 1995; 18: 555-558.

3. Sayeed MA, Mahtab H, Khanam PA, Latif ZA, Keramat Ali SM, Banu A, Ahren Bo and Azad Khan AK. Diabetes and Impaired Fasting Glycemia in a Rural Population of Bangladesh. Diabetes Care 2003; 26: 1034-1039.

4. Zaman MM, Ahmed J, Choudhury SR, Numan SM, Islam MS and Parvin K Prevalence of Metabolic Syndrome in Rural Bangladeshi Women. Diabetes Care 2006; 29:1456-1457.

5. Hussain A, Vaaler S, Sayeed MA, Mahtab H, Ali SMK and Azad Khan AK. Type 2 diabetes and impaired fasting blood glucose in rural Bangladesh: a population-based study. Eur J Public Health 2007; 17(3): 291-296.
6. Ahmed S, Shirin S, Mohsena M, Parvin N, Sultana N, Sayeed S, Mahjabeen R, Akter Masuma and Sayeed MA. Geriatric health problems in a rural community of Bangladesh. Ibrahim Med Coll J 2007; 1(2): 17-20.

7. Ahmed S, Mohsena M, Shirin S et al. Nutritional status, hypertension, proteinuria and glycosuria amongst the women of rural Bangladesh. Ibrahim Med Coll J 2008; 2(1): 21-24.

8. Khan MR et al. Knowledge, attitude and feeding practices among the mothers having under-5 children in a rural community of Bangladesh. Ibrahim Med Coll J 2008; 2(1): 35-36 [Letter].

9. Rasul FB et al. Nutritional status, proteinuria and glycosuria among primary school children in a rural community of Bangladesh. Ibrahim Med Coll J 2008; 2(1): 36-37 [Letter]. 